\title{
RESULTS OF BUCCAL MUCOSAL GRAFT URETHROPLASTY IN MANAGEMENT OF ANTERIOR URETHRAL STRICTURE - EXPERIENCE IN A SINGLE CENTER
}

\author{
MOHAMMAD ABDUL AZIZ1 ${ }^{1}$, SHAFIQUR RAHMAN ${ }^{1}$, MIRZA MAHBUBUL HASAN ${ }^{1}$
}

\begin{abstract}
:
Objective: To share our experience with buccal mucosal graft (BMG) urethroplasty for the management of anterior urethral strictures in BIRDEM General Hospital, Dhaka.

Materials and methods: This study was conducted from January 2013 to January 2018. Patients selected according to inclusion and exclusion criteria. The oral mucosal characteristics were assessed in all patients during the initial workup. Single stage dorsolateral onlay graft urethroplasty done in all patients. They were followed according schedule for outcome and complications.
\end{abstract}

Result:Total 59 patients were studied. Overall success rate of BMG urethroplasty was $88.1 \%$ at $12^{\text {th }}$ month. Complications include development of periurethral abscess (3.4\%), restructure (8.5\%) development of fistula (1.7\%). Total 8 patients underwent retreatment procedures like drainage of periurethral abscess, dilatation, optical internal urethrotomy (OIU) and revision urethroplasty.

Conclusion:The buccal mucosa is easy to obtain and handle, therefore BMG urethroplasty is a safe and effective in managing anterior urethral stricture.

Key Word: Buccal Mucosa, Urethroplasty, Urethral Stricture.

Bangladesh J. Urol. 2019; 22(2): 128-131

\section{Introduction}

Anterior urethral stricture is a pathological fibrous tissue development involving the corpus spongiousum. Common causes are trauma, mostly straddle injury, infection, instrumentation, etc. For management factors to be consider includes etiology of stricture, site, length and density of the fibrous tissue, comorbidities [1]. A long segment of urethral stricture is the indication for surgical correction. Strictures longer than $2 \mathrm{~cm}$ that are not suitable for anastomotic repair therefore, require substitution urethroplasty, where a graft is used. Grafts

1. Department of Urology, BIRDEM General Hospital, Dhaka Correspondences: Dr. Mohammad Abdul Aziz, Registrar, Department of Urology, BIRDEM General Hospital, Dhaka. Mob. 01823234055, email: dr.abdulaziz@live.com

Received: 05 February 2019

Accepted: 10 May 2019 are harvested from different locations which may be pedicled and free grafts. Common grafts are split and full-thickness skin grafts (genital and extra-genital), bladder mucosa, colonic mucosa, tunica vaginalis, tissue-engineered grafts, and intra-oral mucosa (buccal or lingual) $[2,3,4]$. Long-term results of scrotal and extragenital skin are disappointing as non-hirsute fullthickness skin grafts are associated with stricture recurrence [5]. Among the mucosal grafts, the buccal mucosa has proved to be a versatile and successful urethral substitute. The use of buccal mucosa graft (BMG) for urethral reconstruction was first reported, in 1894 [6]. It is relatively easy to obtain and manipulate, is a wet epithelium, and has an excellent immunity. It is less prone to stricture recurrence especially in the presence of lichen sclerosis. Today the buccal mucosa 


\section{2(2) 2019}

Results of Buccal Mucosal Graft Urethroplasty in Management of Anterior Urethral Stricture - Experience in A Single Center

is the preferred donor site for urethral stricture repair [7]. However, its harvesting may be associated with donor site morbidities, such as perioral numbness, difficulty in opening the mouth and less commonly, dry mouth, and long term complications such as scarring [8]. The thick buccal mucosa epithelium with dense submucosa and extensive capillary network assures rapid neo-vascularization and early access of nutrients from the wound bed $[4,9,10]$. Herein we report our experience with buccal mucosal graft (BMG) for the primary repair of anterior urethral strictures in BIRDEM General Hospital, Dhaka.

\section{Materials and Methods}

In this study we collected data of patients who underwent buccal mucosal graft (BMG) urethroplasty for anterior urethral stricture in BIRDEM General Hospital, Dhaka, Bangladesh, from January 2013 to January 2018. Patients with complex strictures (strictures associated with abscess, fistula), posterior urethral strictures, history of oral surgery, visible oral mucosal changes, restricted mouth opening, and previous failed urethroplasty were excluded from the study. Patients who were not attending in follow-up also excluded. Patient characteristics and baseline data were recorded. All patients underwent uroflowmetry (UFM), urine culture/sensitivity, ultrasound of KUB with postvoidal residue (PVR), urethrography, and cystourethroscopy.

The oral mucosal characteristics were assessed in all patients during the initial workup. Single stage dorsolateral onlay graft urethroplasty was applied in all patients. After intubation under general anesthesia, initially perineal dissection was done. Following midline perineal incision, bulbospongiosus muscle was dissected. The urethra was mobilized from cavernosa only on one side beyond midline to preserve the vascular supply. The urethra was opened longitudinally on lateral side. The stricture length was measured. Graft was harvested $2 \mathrm{~cm}$ longer than the measured stricture length, as there is approximate $10 \%$ contraction over time, and width of $15-25 \mathrm{~mm}$ was taken to provide a lumen of at least $24 \mathrm{Fr}$ after tubularization. For BMG urethroplasty, graft taking was started with the submucosal infiltration of xylocaine and adrenaline $(1: 100,000)$ under the marked buccal mucosal patch. Approximately, 0.5-1.0 cm mucosa from Stenson's duct were left to prevent duct injury. All defects were left open to prevent tension, pain, and distortion. After graft harvest, fat removal was done till the graft appeared creamy white. Graft and urethral plate were stretched to avoid postoperative diverticula and postvoid dribbling; attached on cavernosal bodies and after that it was sutured to the urethral plate in dorsolateral onlay fashion. Finally, the urethra was closed over $16 \mathrm{Fr}$ silicone catheter with 5-0 vicryl.

All patients were given intravenous antibiotics for 1 days, followed by oral antibiotic. The patients were allowed liquid diet 6 hours after operation and then gradually soft and regular diet in the following days. In the postoperative period patients were asked to visit outpatient clinic for regular follow-up and reporting the complications. The patients were followed at 1 and 3 weeks then at 3, 6 and 12 months after surgery. Urethral catheter removed at 3 weeks. Voiding symptoms, questionnaires, and uroflowmetry were done in all as primary screening for stricture recurrence. Urethrography and cystourethroscopy were done as a secondary screening only if the patient developed obstructive symptoms or uroflowmetry showed Qmax $<15 \mathrm{ml}$ after ruling out lower urinary tract infection. The success of urethroplasty was considered as the primary outcome of the study. We defined success as the absence of any obstructive symptoms and no need of subsequent procedures, such as dilatation, cystourethroscopy, and internal urethrotomy.

\section{Statistical evaluation}

Data were entered in the MS Excel and analyzed in SPSS version 25 software (IBM Corp. IBM SPSS Statistics for Windows). Continuous variables were presented as means \pm standard deviation. Proportions (percentages) were calculated for discrete variables.

\section{Results}

Total 67 patients underwent BMG urethroplasty for anterior urethral stricture. Among them 8 patients were excluded as they lost follow-up. So, 59 patients, were finally analyzed.

Patients were grouped in 3 age groups (figure-1). Group $A(<35$ years $)=5(8.5 \%)$, group $B(36-55$ year $)=43$ $(72.9 \%)$, Group C (>56 years $)=11(18.6 \%)$. Mean age was $48.3+15.6$.

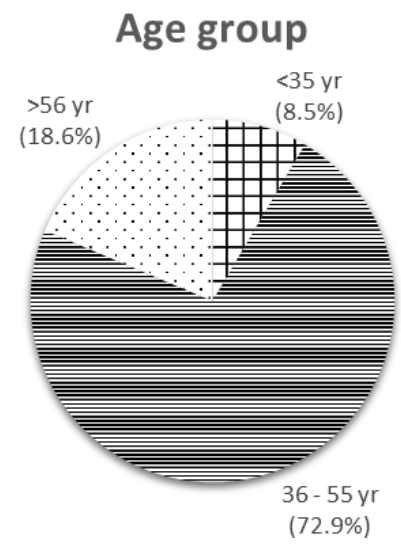

Fig.-1: Age group 
Most of the patient suffered from accidental trauma $(16=27.1 \%)$. Other causes are infection like urethritis (11 $=18.6 \%)$, Fournier's gangrene $(5=8.5 \%) .9(15.2 \%)$ patients had associated Lichen sclerosis. $3(5.1 \%)$ gave history of hypospaedius repair and others gave history of instrumentation like faulty urinary catheter insertion $(9=15.2 \%)$ and TURP $(6=10.2 \%)$. (Figure 2$)$.

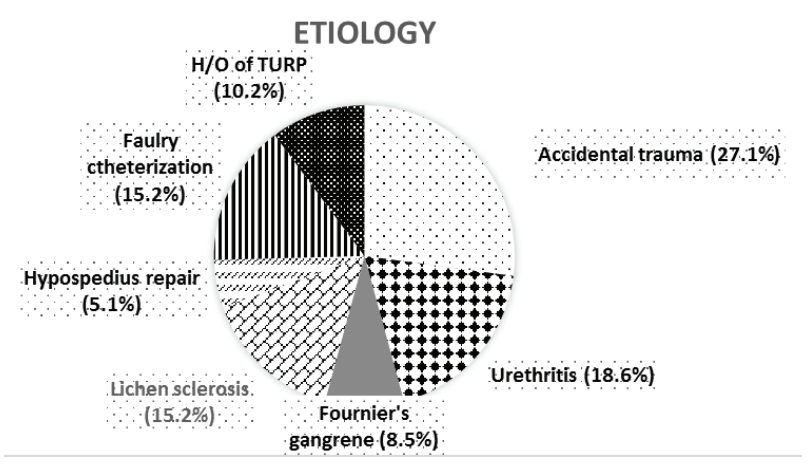

Fig.-2. Etiology

The stricture length ranged from 2.5 to $6 \mathrm{~cm}$ (mean $4.2 \pm 1.7$ ). As BIRDEM General Hospital deals with a large number of diabetic patients; most of our patient $(48=81.3 \%)$ was diabetic. In large number of them diabetes was uncontrolled $(41=69.5 \%)$. Many of them multiple comorbidities.

During follow-up at $1^{\text {st }}$ week 2 patients $(3.4 \%)$ developed periurethral abscess. Both of them were unable to keep their diabetes control following discharge at home. One patient suffered from early loss of catheter due to accidental pull at $2^{\text {nd }}$ week. He subsequently developed stricture at follow-up at $3^{\text {rd }}$ month along with two other patient who also developed stricture $(3=5.1 \%)$. Two of them underwent dilatation and another underwent optical internal urethrotomy (OIU) with subsequent self-dilatation. On $6^{\text {th }}$ month follow-up one patient $(1.7 \%)$ developed urethrocutaneous fistula and it was repaired. During follow-up at $12^{\text {th }}$ week 4 patients developed stricture; among them two had previous stricture. Two of them underwent OIU with subsequent self-dilatation and in two cases repeat BMG urethroplasty done. So overall success rate at 12 month was $88.1 \%$.

Table-I

Complications

\begin{tabular}{lc}
\hline Complication & No \\
\hline Periurethral abscess & $2(3.4 \%)$ \\
Early loss of catheter & $1(1.7 \%)$ \\
Stricture & $5(8.5 \%)$ \\
Fistula 1(1.7\%) & \\
\hline
\end{tabular}

Table-II

Procedures done for managing complications

\begin{tabular}{lc}
\hline Procedure & No of patient \\
\hline Drainage of periurethral abscess & 2 \\
Dilatation & 2 \\
OIU & 3 \\
Repeat urethroplasty & 2 \\
\hline
\end{tabular}

Early and immediate graft donor site complications were seen in all patients. Pain, difficulty in chewing and numbness of donor site was the most common early complication, but these were mild and transient in all patients. Salivary flow changes not seen in any patient.

\section{Discussion}

Severe and longer urethral strictures require substitution urethroplasty. Miscellaneous tissues have been used in the past however, in the last decade, buccal mucosa gained popularity as the best substitute material for urethral reconstruction [11]. Buccal mucosa is a convenient donor site for augmentation urethroplasty because of its thick epithelium, high content of elastic fibers and rich vascularity due to pan laminar plexus, and good graft uptake [12]. It is easy to obtain, readily available, compatible with wet environment.

A systematic review and meta-analysis of urethral reconstruction with buccal mucosa or penile skin graft (PSG) revealed a success rate of $85.9 \%$ with buccal mucosa and $81.8 \%$ with PSG [13]. A $87 \%$ success rate has been reported when using buccal mucosa dorsal onlay free grafts for the management of bulbar urethral strictures to treat 24 patients [11]. In the series of Basri, et al. success rate of BMG urethroplasty for anterior urethral stricture was $67.7 \%$ [14]. In our series, 59 patients underwent buccal mucosa urethroplasty for anterior urethral stricture. The overall medium to longterm success rate in our small series is $88.1 \%$ at 12 th month. This finding is compatible with international studies.

In the series of Basri, et al. during follow-up $40 \%$ patient developed re-stricture and $6.7 \%$ developed fistula [14]. In our series only $8.5 \%$ developed re-stricture and $1.7 \%$ developed fistula. However $3.4 \%$ developed periurethral abscess due to uncontrolled diabetes.

In the present series, pain, difficulty in chewing and numbness of donor site were the most common early 


\section{2(2) 2019}

Results of Buccal Mucosal Graft Urethroplasty in Management of Anterior Urethral Stricture - Experience in A Single Center

complication. No long-term complications, such as sensory nerve deficit, or damage to Stenson's duct occurred. In parallel to this observation, several authors have reported no important oral complications in their respective studies [15-17]. However, in a retrospective review of 49 male patients it was found that $15(26 \%)$ had residual perioral numbness after 6 months, with $5(9 \%)$ having persistent restriction in mouth opening [18-20].

In association with follow-up duration, it is known that all urethral grafts tend to shrink over time. One can claim that, a longer follow-up period is likely to produce poorer results. In this present study the follow-up period of 12 months may be the limitation of the study. Nevertheless, in the presence of different stricture etiologies and various parameters such as location, length and surgical techniques, a large prospective randomized trial comparing graft materials and/or techniques would be extremely difficult to design. Therefore, despite the relatively small number of patients of our study, the present results seem to contribute modestly to the fact that BMG urethroplasty is a suitable method in substitution urethroplasty.

\section{Conclusions}

Although the sample size is small, our study suggest that anterior urethral strictures up to $6 \mathrm{~cm}$ in length may be effectively managed with BMG urethroplasty. The buccal mucosa is easy to obtain and handle. Furthermore, the rate of complications, from both a urological and oropharyngeal perspective is low.

\section{References}

1. Jordan GH, McCammon KA. Surgery of the penis and urethra. Campbell-Walsh urology. 10th ed. Philadelphia: Elsevier Saunders. 2012; p. 9561000

2. Andrich DE, Mundy AR. What is the best technique for urethroplasty? Eur Urol. 2008; 54:1031-1041

3. Lumen N, Oosterlinck W, Hoebeke P. Urethral reconstruction using buccal mucosa or penile skin grafts: systematic review and meta-analysis. Urol Int. 2012; 89:387-394.

4. Mangera A, Chapple C. Management of anterior urethral stricture: an evidence-based approach. Curr Opin Urol. 2010; 20:453-458.

5. Rogers HS, McNicholas TA, Blandy JP. Long-term results of onestage scrotal patch urethroplasty. Br J Urol. 1992; 69:621-628.

6. Sievert KD, Seibold J, Schultheiss D, et al. Reconstructive urology in the change, from its beginning to the close future. Urologe A. 2006; 4:52-8.

7I Bhargava S, Chapple CR. Buccal mucosal urethroplasty: is it the new gold standard? BJU Int. 2004; 93:1191-1193

8. Wood DN, Allen SE, Andrich DE, et al. The morbidity of buccal mucosal graft harvest for urethroplasty and the effect of nonclosure of the graft harvest site on postoperative pain. $\mathrm{J}$ Urol. 2004; 172:580-3.

9. Bhargava S, Chapple CR. Buccal mucosal urethroplasty: is it the new gold standard? BJU Int. 2004; 93:1191-1193.

10. Dubey D, Vijjan V, Kapoor R, et al. Dorsal onlay buccal mucosa versus penile skin flap urethroplasty for anterior urethral strictures: results from a randomized prospective trial. J Urol. 2007; 178:2466-2469.

11. Djordjevic ML. Graft surgery in extensive urethral stricture disease. Curr Urol Rep. 2014; 15:424.

12. Pansadoro V, Emiliozzi P, Gaffi M, et al. BMU in the treatment of bulbar urethral strictures. Urology. 2003; 61:1008-1010.

13. Lumen N, Oosterlinck W, Hoebeke P. Urethral reconstruction using buccal mucosa or penile skin grafts: systematic review and meta-analysis. Urol Int. 2012; 89:387-394.

14. Basri Cakiroglu, et al. Outcome of buccal mucosa urethroplasty in the management of urethral strictures. Archivio Italiano di Urologia e Andrologia 2017; 89, 2:139-142.

15. Grady JD, McCammon K, Schlossberg SM, et al. Buccal mucosal graft for penile urethral strictures. J Urol. 1999; 161:375.

16. Morey AF, McAninch JW. Technique of harvesting buccal mucosa for urethral reconstruction. J Urol. 1996; 155:1696-1697.

17. Eppley BL, Keating M, Rink R. A buccal mucosal harvesting technique for urethral reconstruction. J Urol. 1997; 157:1268-1270.

18. Dublin N, Stewart LH. Oral complications after buccal mucosal graft harvest for urethroplasty. BJU Int. 2004; 94:867-869.

19. Caldamone AA, Edstrom LE, Koyle MA, et al. Buccal mucosal grafts for urethral reconstruction. Urology. 1998; 51(5A Suppl):15-19.

20. Kane CJ, Tarman GJ, Summerton DJ, et al. Multiinstitutional experience with buccal mucosa onlay urethroplasty for bulbar urethral reconstruction. J Urol. 2002; 167:1314-1317. 